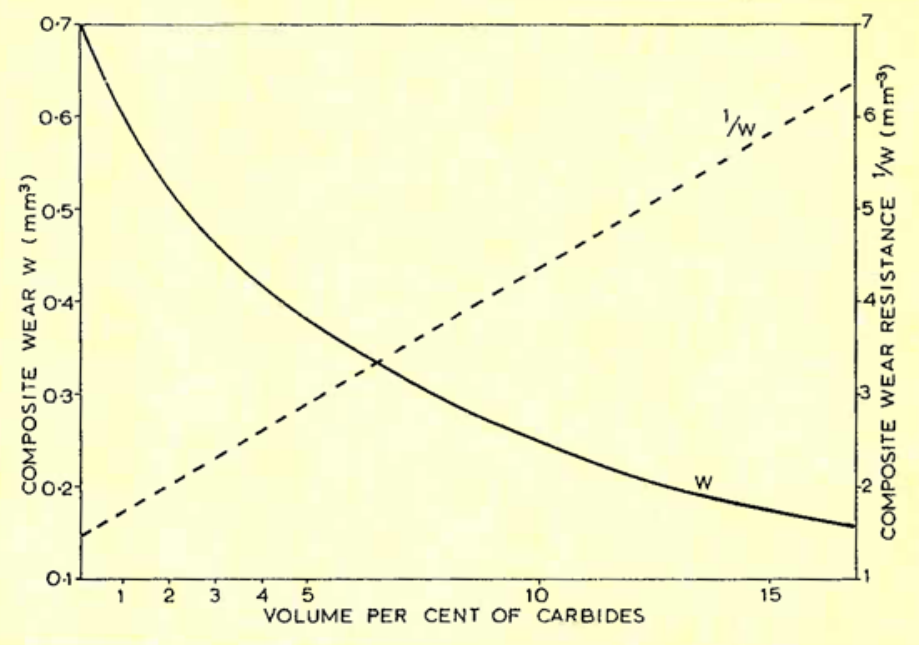

Fig. 4 Dependence of composite wear and wear resistance on the amount of carbide present in the gold deposit. All four systems investigated-acid cyanide and alkaline sulphite golds with titanium and tungsten carbides - gave approximately the same relationship

composites. It is probable that mechanical restraint of matrix deformation by the hard non-deformable particles plays an important role in strengthening.

\section{Conclusions}

Composite gold-refractory carbide coatings formed by electrodeposition have been found to have considerably enhanced hardness, strength, and rubbing wear characteristics compared to gold electroplate. Because the carbide particles are chemically inert the corrosion resistance and electrical contact resistance properties approach those of pure gold.

It is considered that such deposits could find extensive use in sliding contact applications in which exposure and tarnishing of substrate base metal through wear of the gold plate is a problem. Similar considerations may encourage the use of composite gold electroplates in decorative jewellery applications especially with the possibility of obtaining various attractive finishes by varying the size and volume of co-deposited particles.

\section{Acknowledgements}

The author would like to thank the Chamber of Mines of South Africa for its support of this work and for permission to publish this paper. Acknowledgement is also made to Mr. M. A. R. Baig, now with Precision Circuits Ltd., Hayes, England, for his contribution to the research.

\section{References}

1 F. K. Sautter, "Electrodeposition of Dispersion Strengthened $\mathrm{Au}-\mathrm{Al}_{2} \mathrm{O}_{3}$ Alloys", Watervliet Arsenal Tech. Rept., 1963 RR-6321

2 F. K. Sautter, Metall, 1964, 18, (6), 596

3 M. L. Gimpl and N. Fuschillo, Metal. Soc. Conf., "Oxide Dispersion Strengthening", 1966, 47, 719, Publ. by Gordon \& Breach

4 N. Fuschillo and M. L. Gimpl, F. Mater. Sci., 1970, 5, 1078

$5 \mathrm{M}$. Poniatowski and M. Clasing, Gold Bull., 1972, 5, (2), 34

6 H. R. Peiffer et al., Proc. 17th Ann. Nat. Relay Conf., 1969, 1

7 M. Antler, ASLE Trans., 1962, 5, 297

8 F. K. Sautter, F. Electrochem. Soc., 1963, 110, 557

9 F. J. Dunkerley et al., Metal. Soc. Conf. "Oxide Dispersion Strengthening", 1966, 47, 695

10 V. P. Greco and W. Baldauf, Plating, 1968, 55, 250

11 M. Pushpavanam et al., Metal Finish, 1974, 72, (10), 46

12 N. Guglielmi, f. Electrochem. Soc., 1972, 119, 1009

13 D. S. R. Brown and K. V. Gow, Plating, 1972, 59, 437

\title{
Bibliographic Reviews on the Electrodeposition of Gold Alloys
}

While the extensive literature on gold plating is readily available, the subject of the deposition of gold alloys-in which so much interest is now being taken-is not so well documented. Published information in this field has now been assembled by $\mathrm{Dr}$ W. S. Rapson of the Chamber of Mines of South Africa Research Organisation and has been incorporated in a series of bibliographical reviews as follows:

Part I Electrodeposition of gold with copper and silver

Part II Electrodeposition of gold with zinc, cadmium, gallium, indium, thallium, tin, lead, antimony and bismuth

Part III Electrodeposition of gold with cobalt, nickel and iron

Part IV Electrodeposition of gold with the platinum group metals, and with chromium, molybdenum, uranium, tungsten and manganese.

Copies of these reviews may be obtained by writing to the Research Organisation, Chamber of Mines of South Africa, P.O. Box 809, Johannesburg, South Africa. 